\title{
Research on Influence of Online Review Based on ELM Model on Sales of Beauty Products
}

\author{
Yao Liang \\ Wuhan University of Technology \\ School of Management \\ Wuhan, China \\ 269493944@qq.com
}

\author{
Hu Wang \\ Wuhan University of Technology \\ School of Management \\ Wuhan, China
}

\begin{abstract}
At present, online reviews have an increasingly greater influence on consumer purchasing decisions. This article expands the review dimensions based on the ELM model according to the characteristics of the beauty products, and uses multiple regression analys is to explore the impact of online revie ws on the sales of beauty products. The research conclusions show that there are significant positive effects on sentiment in terms of comment sentiment, number of reviews, and store cre dit in the core path; the number of image reviews and the number of collections in the peripheral path positively influence sales, while the number of reviews has a negative effect on sales. In addition, consumer characteristics and product characteristics play a regulatory role in the model.
\end{abstract}

Keywords-ELM model; Online review; Beauty products; Sales; Regression analysis

\section{INTRODUCTION}

In online spending, consumers are accustomed to browsing buyers' online reviews in order to make purchasing decisions ${ }^{[\mathrm{f}]}$ Current related research often selects comment bias, comment quantity, and comment dispersion in online reviews to measure online reviews. Wu Jiang proposed that the usefulness of consumer perception reviews is influenced by the relevance, objectivity, and timeliness of the review information ${ }^{[2]}$. The ELM model has been widely used in consumer behavior research. Filieri's research suggests that ELM is applied to online reviews for individual consumer decisions, and the quality of reviews influences individual decision-making through a central path ${ }^{[3]}$. Therefore, this article expands the research dimensions of the beauty product reviews, considers the effects of regulatory effects, and discusses the impact of online reviews on the network sales of beauty products.

\section{MODEL CONSTRUCTION AND RESEARCH HYPOTHESES}

\section{A. ELM-based multi-dimensional conceptual model}

This article uses the comment dimension and store dimension as core and peripheral paths. In the core path, the comment dimension includes the comment sentiment trend and the number of reviews, and the store dimension refers to the store reputation score. In the peripheral path, the comment dimension includes the number of additional comments and the number of picture comments, and the store dimension refers to the number of favorites. In addition, the consumer dimension and the product dimension are used as adjustment variables to study the effect of membership level and product type on the adjustment of product sales.

TABLE I. STUDY VARIABLE SELECTION TABLE

\begin{tabular}{|c|c|c|c|}
\hline \multicolumn{2}{|c|}{ Variable category } & Variable name & Variable definitions \\
\hline \multirow{6}{*}{$\begin{array}{l}\text { Independent } \\
\text { variable }\end{array}$} & \multirow{4}{*}{$\begin{array}{l}\text { Comment } \\
\text { dimension }\end{array}$} & Comment emotion A1 & Product evaluation score \\
\hline & & Number of comments A2 & $\begin{array}{l}\text { The number of reviews for the } \\
\text { product }\end{array}$ \\
\hline & & $\begin{array}{c}\text { Number of additional } \\
\text { comments A3 }\end{array}$ & Product additional comments \\
\hline & & $\begin{array}{c}\text { Number of picture } \\
\text { comments A4 }\end{array}$ & Quantity of product reviews \\
\hline & \multirow{2}{*}{$\begin{array}{c}\text { Store } \\
\text { dimension }\end{array}$} & Store reputation A5 & $\begin{array}{l}\text { Average score of shop service, } \\
\text { description, and logistics }\end{array}$ \\
\hline & & Collection quantity A6 & $\begin{array}{l}\text { The number of times that a } \\
\text { product was added to a favorite }\end{array}$ \\
\hline $\begin{array}{c}\text { Dependent } \\
\text { variable }\end{array}$ & $\begin{array}{c}\text { Sales } \\
\text { dimension }\end{array}$ & Monthly sales Y & Monthly volume of the product \\
\hline \multirow[b]{2}{*}{ Moderator } & $\begin{array}{l}\text { Consumer } \\
\text { dimension }\end{array}$ & Membership level B1 & $\begin{array}{l}\text { "0" stands for super affiliate, } \\
\text { "1" stands for ordinary affiliate }\end{array}$ \\
\hline & $\begin{array}{l}\text { Product } \\
\text { dimension }\end{array}$ & Product type B2 & $\begin{array}{l}\text { "0" represents an experiential } \\
\text { product, "1" represents a } \\
\text { search product }\end{array}$ \\
\hline
\end{tabular}

\section{B. Research hypothesis}

1) Core Path

In this study, the evaluation of emotions, the number of reviews, and the reputation of the store are taken as the core path. Consumers are very concerned about the emotional tendencies of the reviews and the store's reputation score when they purchase the goods, and the changes in attitude caused by the consumers are more obvious than other factors.

\section{a) Comment dimension}

The results of existing online reviews show that the polarity of reviews significantly influences consumer decision-making. Zhao Jianbin believes that when the review price is positive, the objective attributed review presents more purchase reasons that are directly related to the product's attributes. Perceived reviews are more useful ${ }^{[4]}$. The number of reviews is a reflection of the overall size of online reviews, and the number of online reviews often positively affects product sales. Guo conducted research on Amazon's data of 332 new products over the past nine months and found that review valence and number of reviews have a strong influence on search products $^{[5]}$.

H1: Commentary emotion has a significant positive effect on sales. 
H2: The number of reviews has a significant positive effect on sales.

\section{b) Store dimension}

The reputation of the shop is an important indicator of the integrity of the seller. The shop with a high reputation score indicates that the shop is highly reliable. Li Huifang found that the quality of logistics services has a positive effect on customer satisfaction and customers' repeated purchase intentions ${ }^{[6]}$. This article takes the average score of service, description and logistics as the shop credit score.

H3: Store credit has a significant positive effect on sales.

\section{2) Peripheral path}

This article regards popular degree and additional features of reviews as peripheral paths, and many consumers pay great attention to popularity and commentary additional features. This information has a certain impact on consumer decisionmaking.

\section{a) Comment dimension}

Many consumers carefully observe the additional review information at the final decision stage. Wang Changzheng pointed out that consumers often use supplemental comments to supplement or revise their views and attitudes for initial comments after the initial review has been published ${ }^{[7]}$. Through the picture comments, consumers can see the effect of the "buyer show", which reduces the risk of online shopping. Chen Zhengliang believes that improving the proportion and quantity of picture comments can make picture comments play a better role in evaluation, feedback, and reference ${ }^{[8]}$.

H4: The quantity of product reviews has a significant positive impact on sales.

H5: The number of picture reviews for a product has a significant positive effect on sales.

\section{b) Store dimension}

The degree of popularity refers to the number of consumers' collection of the product. When the quantity of a product is increased, the volume of goods will be more. Zhang Hongyu's research based on public commentaries on 10,461 sample restaurants shows that word-of-mouth ratings can positively influence consumer page views, collections, and attendance ${ }^{[9]}$.

H6: The quantity of goods collected has a significant positive effect on the sales of goods.

\section{3) Adjusting the path}

\section{a) Consumer dimension}

Because the number of online shopping of super-members is more and online shopping experience is more abundant, online reviews have more interactions and are more likely to regulate the impact of online reviews on product sales. However, the research findings of different scholars are not the same. After Li Jian conducted an empirical analysis of 183 mobile phone reviews of Amazon.com, he pointed out that the prestige of the reviewers had little impact on customers and had no significant effect on sales ${ }^{[10]}$.
H7a: Consumer Membership Level Regulates the impact of online reviews on online sales. Compared with ordinary members, the super membership comment dimension has a greater impact on sales.

H7b: Consumer Membership Level Regulates the impact of online reviews on online sales. Compared to ordinary members, the super member store dimension has a greater impact on sales.

\section{b) Product dimension}

Beauty products often have two types of search-type products and experience-type products. In its study, Yang Ming et al. proposed that when analyzing the utility of online product reviews, the types of goods should be considered, and different types of products have different content[11]. Therefore, this article makes the following assumptions:

H8a: Product type regulates the impact of online reviews on online sales. Compared with search-based products, the consumer review dimension has a greater impact on the sales of experiential products.

H8b: Product type regulates the impact of online reviews on online sales. Compared with search-type products, the store dimension has a greater impact on the sales of experiential products.

\section{DATA ANALYSIS}

\section{A. Data Collection}

This article captures data on female beauty products in the Tmall Mall website. Select six sample beauty products with a certain price range, and collect all review data for the period ending on November 24, 2017. After the data was preprocessed, 60 online reviews of experience-based women's products and 60 online reviews of search-based women's products were collected. A total of 234,850 valid samples. This article divides product types into search-type and experiencetype products, each selecting three representative products for research.

\section{B. Descriptive statistical analysis}

In this paper, a descriptive statistical analysis of the variables in the model was conducted, and the average score of comments was 4.802 points. The average number of comments is 68,931 , and the minimum value is 1,080 online comments, with a maximum value of up to 230,000 . The average value of shop reputation is 4.778 , which is close to 5 stars. The average of the membership level is 0.169 . The monthly maximum sales value of commodities is 316015 , and the minimum value is 187 . The above data are all in a reasonable distribution. 
TABLE II. DESCRIPTIVE ST ATISTICS

\begin{tabular}{|c|c|c|c|c|}
\hline & Minimum & Maximum & Average value & Standard deviation \\
\hline Comment emotion & 4.6 & 4.9 & 4.802 & 0.616 \\
\hline Number of comments & 1080 & 524589 & 68931.30 & 125043.952 \\
\hline $\begin{array}{c}\text { Number of additional } \\
\text { comments }\end{array}$ & 31 & 23046 & 1906.64 & 4219.442 \\
\hline $\begin{array}{c}\text { Number of picture } \\
\text { comments }\end{array}$ & 86 & 61497 & 6249.74 & 11397.492 \\
\hline Store reputation & 4.667 & 4.833 & 4.77850 & 0.040306 \\
\hline Collection quantity & 2477 & 699258 & 118226.24 & 166891.480 \\
\hline Membership level & 0.04 & 0.41 & 0.1694 & 0.07449 \\
\hline Monthly sales & 187 & 316015 & 33721.00 & 63657.329 \\
\hline
\end{tabular}

\section{Multiple Regression Analysis}

This section will use multiple regression analysis methods to further explore the causal relationship between the various variables. According to the multi-dimensional conceptual model of this paper, three regression models are constructed, in which model 1 is a regression analysis under the condition of only three explanatory variables of the central path, and model 2 is under the condition of three explanatory variables containing only the edge path. In the regression analysis, Model 3 integrates the central path and the marginal path to observe the regression of a total of six variables.

\section{TABLE III. MULTIPLE REGRESSION ANALYSIS RESULTS}

\begin{tabular}{|l|c|c|c|}
\hline & Model1 & Model 2 & Model 3 \\
\hline Comment emotion & $0.248^{*}$ & & $0.234^{*}$ \\
\hline Number of comments & $0.666^{* *}$ & & $0.575^{* *}$ \\
\hline Store reputation & $0.160^{*}$ & & $0.172^{*}$ \\
\hline $\begin{array}{l}\text { Number of additional } \\
\text { comments }\end{array}$ & & $-0.378^{*}$ & $-0.767^{*}$ \\
\hline Number of picture comments & & $1.196^{* *}$ & $1.003^{* *}$ \\
\hline Collection quantity & & $0.441^{*}$ & $0.552^{* *}$ \\
\hline $\mathrm{R}^{2}$ & 0.749 & 0.78 & 0.832 \\
\hline $\mathrm{F}$ & $45.635^{* *}$ & $54.215^{* *}$ & $35.433^{* *}$ \\
\hline Number of samples & 120 & 120 & 120 \\
\hline
\end{tabular}

From the statistical data, it can be seen that in Model 1, Model 2 and Model 3, the F statistic values are obviously different from $0(\mathrm{P}<0.001)$, reaching a significant level, so the construction of each regression model is reasonable. Compared with Model 1 and Model 2, Model 3 has a significant improvement in R2, indicating that the coexistence of the core path and the peripheral path is of practical significance. Analyze the regression results of Model 3, and the values of the comments sentiment, number of reviews, and store reputation in the core path are all positive numbers. Through significant tests, it shows that commentary emotions, number of comments, store reputation, and product sales are significantly positive. Correlation relationship. The coefficient of the picture comments and number of collections in the peripheral path is positive, and through significant tests, it shows that the number of pictures review and collection has a significant positive correlation with the sales of the product. However, the coefficient of the additional review is negative, indicating that the number of additional reviews is negatively related to the sales of the product.

\section{Regulation Effect Analysis}

\section{1) Core Pathway Adjustment Effect}

As can be seen from the data in the table, Model 4 is a model with only the core route independent variables, and the adjustment variables are added. There is a significant positive correlation between comment emotions, number of reviews and shop reputation and network sales of products. At the same time, except for the interaction items "Store Reputation* Product Type" and "Store Reputation* Membership Level" which did not pass the significance test, other interaction items passed the significance test.

TABLE IV. CORE PATHWAY EFFECT ANALYSIS RESULTS

\begin{tabular}{|l|c|}
\hline & Model 4 \\
\hline Comment emotion & $0.234^{*}$ \\
\hline Number of comments & $0.814^{* *}$ \\
\hline Store reputation & $0.132^{*}$ \\
\hline Comment Emotion* Membership Level & $0.292^{*}$ \\
\hline Number of comments* membership level & $0.572^{* *}$ \\
\hline Store Reputation* Membership Level & 0.091 \\
\hline Comment Emotion* Product Type & $0.114^{*}$ \\
\hline Number of reviews * product type & $0.357^{* *}$ \\
\hline Store Reputation* Product Type & -0.081 \\
\hline $\mathrm{R}^{2}$ & 0.771 \\
\hline $\mathrm{F}$ & $12.566^{* *}$ \\
\hline
\end{tabular}

The type of product has a regulatory effect on the relationship between commentary emotion, number of reviews, and product sales, but does not have a regulatory effect on the relationship between store credit and product sales. Assume that $\mathrm{H} 7 \mathrm{~b}$ has not been verified. In terms of the level of membership, the higher the level of membership, the greater the impact of the same commentary on product sales. This also means that the average consumer has a more trusting attitude towards the reviews posted by users with higher ratings.

\section{2) Peripheral Path Adjustment Effect}

From the data in the table, it can be seen that Model 5 adds a control variable to the basic model with only the peripheral path arguments. In addition to the interaction items "collection quantity * membership level" and "collection quantity * product type" that failed the significance test, other interaction items passed the significance test.

TABLE V. PERIPHERAL PATH ADJUST MENT EFFECT ANALYSIS RESUlTS

\begin{tabular}{|l|c|}
\hline & Model 5 \\
\hline Number of additional comments & $-0.164^{*}$ \\
\hline Number of picture comments & $0.572^{* *}$ \\
\hline Collection quantity & 0.144 \\
\hline Number of additional comments* Membership Level & $-0.855^{* *}$ \\
\hline Number of picture comments* membership level & $1.674^{* *}$ \\
\hline Collection quantity* Membership Level & 0.088 \\
\hline Number of additional comments * Product Type & $1.442^{*}$ \\
\hline Number of picture comments* product type & $0.860^{* *}$ \\
\hline Collection quantity* Product Type & 0.164 \\
\hline $\mathrm{R}^{2}$ & 0.881 \\
\hline $\mathrm{F}$ & $25.5^{* *}$ \\
\hline
\end{tabular}

In the peripheral path, the type of merchandise has a significant role in regulating the relationship between the number of reviews, the number of pictures, and the sales volume of goods, while different types of goods have no significant regulatory effect on the relationship between the 
number of collections and the sales volume. In terms of the level of membership adjustment, the higher the level of membership, the same number of reviews and the number of images will have an impact on product network sales. Based on the above analysis, Table VI summarizes whether the empirical analysis supports the model assumptions.

TABLE VI. MODEL HYPOTHESIS RESULT S

\begin{tabular}{|c|c|c|}
\hline Hypothesis & Assumed content & Test result \\
\hline $\mathrm{H} 1$ & Commenting on emotion has a significant positive effect on sales. & support \\
\hline $\mathrm{H} 2$ & The number of reviews has a significant positive effect on sales. & support \\
\hline H3 & Store credit has a significant positive effect on sales. & support \\
\hline $\mathrm{H} 4$ & The number of follow-up reviews has a significant positive effect on sales. & $\begin{array}{l}\text { reverse } \\
\text { support }\end{array}$ \\
\hline H5 & The number of pictures has a significant positive effect on sales. & support \\
\hline H6 & The number of collections has a significant positive effect on sales. & support \\
\hline $\mathrm{H7a}$ & $\begin{array}{l}\text { The consumer's membership level regulates the impact of online reviews on sales. Compared with ordinary members, the super membership } \\
\text { comment dimension has a greater impact on sales. }\end{array}$ & support \\
\hline $\mathrm{H} 7 \mathrm{~b}$ & $\begin{array}{c}\text { The consumer's membership level regulates the impact of online reviews on sales. Compared to ordinary members, the super member store } \\
\text { dimension has a greater impact on sales. }\end{array}$ & not support \\
\hline H8a & $\begin{array}{l}\text { Product Type Regulates the impact of online reviews on sales. Compared with search-based products, the consumer review dimension has a } \\
\text { greater impact on the sales of experiential products. }\end{array}$ & support \\
\hline H8b & $\begin{array}{c}\text { Product Type Regulates the impact of online reviews on sales. Compared with search-type products, the store dimension has a greater impact } \\
\text { on the sales of experiential products. }\end{array}$ & not support \\
\hline
\end{tabular}

\section{CONCLUSION}

This paper captures the transaction data of beauty products and builds a multi-dimensional model based on ELM. It incorporates adjustment variables of membership levels and product categories for empirical analysis, and discusses in depth the impact of consumer online reviews on the sales of beauty products network. The comments sentiment, number of reviews, and store credit in the core path all have a significant positive effect on the network sales of the product. In the peripheral path, the number of picture comments and the number of collections have positively affected the sales of products, and the number of reviews is negatively affecting the sales of products. Consumer characteristics and product characteristics play a regulatory role in the impact of online reviews on product network sales. The higher the level of membership, the greater the impact of published online reviews on sales. For product features, online reviews have a stronger regulatory effect on experiential products. However, the effect of the consumer characteristics and product characteristics on the sales dimension of the store dimension is not significant.

\section{REFERENCES}

[1] Zhang Yanhui,Li Zongwei. Research on Influencing Factors of Usefulness of Online Comments: Based on Product Type Adjustment Effect[J].Management Review,2016,28(10):123-132.

[2] Wu Jiang, Liu Bending. Research on the Influencing Factors of the Effectiveness of Online Commodity Reviews Based on Information Adoption Theory[J]. Journal of Information Resources Management, 2017(1):47-55.

[3] Filieri R, Mcleay F. E-WOM and accommodation: an analysis of the factors that influence travelers' adoption of information from online reviews.[J]. Journal of Travel Research, 2014, 53(1):44-57.

[4] Zhao Jianbin, Tao Jianrong. The Impact of Customer Evaluation Information on Consumer Preferences: The Role of Time Distance Adjustment[J]. Economics \& Management Review, 2014(2):60-66.

[5] Cui G, Lui H K, Guo X N. The Effect of Online Consumer Reviews on New Product Sales[J]. International Journal of Electronic Commerce, 2012, 17(1):39-58.

[6] Li Huifang. Longitudinal Study on the Behavior, Signal and Sales Performance of E-commerce Platform Sellers[D]. Anhui: University of Science and Technology of China, 2015.

[7] Wang Changzheng, He Wei, Wang Kui. Usefulness Perception of Additional Comments in Internet Word of Mouth[J]. Management Science, 2015, 28(3):102-114.

[8] Chen Zhengliang. Research on the Influencing Factors of the Consumer Willingness of Photographs for Electronic Commerce[D]. Harbin: Harbin Institute of Technology, 2015.

[9] Zhang Hongyu, Zhou Tingrui, Yan Huan, et al. The Impact of Internet Word of Mouth on Consumer Online Behavior[J]. Management World, 2014(3):178-179.

[10] Li Jian. The Impact of Online Product Reviews on Product Sales[J]. Modern Information, 2012, 32(1):164-167.

[11] Yang Ming, Yan Xi, Yan Xiangbin, et al. Research on Utility Analysis of Online Commodity Reviews[J]. Journal of Management Science, 2012, 15(5):65-75. 